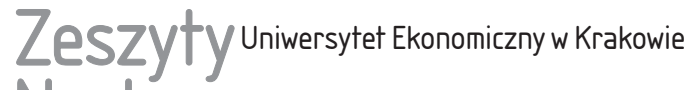 Naukowe
}

\section{Super-replication of European Options with Convex Payoff under Proportional Transaction Costs*}

\begin{abstract}
The paper examines the super-replication of contingent claims in a discrete time financial market with proportional transaction costs. The sole assumption on stock price dynamics is that the returns are bounded. The class of path-dependent European options with nonnegative convex payoff functions is considered. It is proved that the pricing of this type of options can be studied through the pricing of a suitable binomial model. As a consequence, it is shown that the pricing algorithm, which is essentially a dynamic programming procedure on a tree, can be used when the set of possible scenarios is not finite.
\end{abstract}

Keywords: super-replication, transaction costs, model uncertainty, European options. JEL Classification: G13, C61, D52.

\section{Introduction}

This article examines the super-replication of European options in a discrete time market model with transaction costs and volatility uncertainty. Such a problem naturally arises in various applications when European options are

Agnieszka Rygiel, Cracow University of Economics, Faculty of Finance and Law, Department of Mathematics, Rakowicka 27, 31-510 Kraków, e-mail: agnieszka.rygiel@uek.krakow.pl

* The research was financed from the funds granted to the Faculty of Finance and Law at Cracow University of Economics, within the framework of the subsidy for the maintenance of research potential. 
priced. It is therefore not surprising that this issue has been studied fairly widely. The pricing and hedging of contingent claims under proportional transaction costs in the classical case has also been studied in a number of papers (Stettner 1997, Kociński 2004, Roux, Tokarz \& Zastawniak 2008). Option pricing is closely related to the arbitrage under transaction costs studied in (Guasoni, Lépinette \& Rásonyi 2012, Guasoni, Lépinette \& Schachermayer 2008, Jouini \& Kallal 1995, Schachermayer 2003).

A classical probabilistic model of a financial market consists of a measurable space $(\Omega, \mathcal{F})$ and a probability measure $\mathbb{P}$ determining the distribution of stock prices. In contrast, for this paper we studied a distribution not assumed to be (completely) known a priori. Our sole assumption on the stock price dynamic is that the absolute value of the log-returns is bounded from both below and above. The problem of super-replication in such a discrete-time model, with more general nonlinear transaction costs, is studied in (Bank, Dolinsky \& Gökay 2016). The result, including the special case of a convex payoff profile, seems to be nontrivial when applied to the real market from point of view of the calculations. A. Roux, K. Tokarz and T. Zastawniak (2008) developed a pricing and hedging algorithm in the discrete setting under proportional transaction costs, which can be rapidly implemented on a computer, but does not allow for models with uncertain volatilities.

The aim of this paper is to show that pricing of convex European options can be reduced to studying the pricing of a suitable binomial model following the arguments of P. Bank, Y. Dolinsky and S. Gökay (2016) as well as A. Roux, K. Tokarz and T. Zastawniak (2008). The method presented leads to a feasible procedure which can be applied to options with convex payoffs in an uncertain volatility model with arbitrary proportional transaction costs.

\section{Description of the Model}

Let us consider a discrete time market model with a time horizon $N \in \mathbb{N}$ with a riskless savings account $B_{n}=1, n=0, \ldots, N$ and a risky stock $S_{n}>0, n=0, \ldots, N$. Let

$$
X_{n}:=\ln \left(\frac{S_{n}}{S_{n-1}}\right)
$$

be the log-return for period $n=1, \ldots, N$ such that

$$
\underline{\sigma} \leq\left|X_{n}\right| \leq \bar{\sigma}, n=1, \ldots, N
$$

for some constants $0 \leq \underline{\sigma} \leq \bar{\sigma}<\infty$. Hence 


$$
S_{n}=S_{0} \exp \left(\sum_{m=1}^{n} X_{m}\right), n=0, \ldots, N
$$

Let

$$
\Omega=\Omega_{\underline{\sigma}, \bar{\sigma}}:=\left\{\omega=\left(x_{1}, \ldots, x_{N}\right) \in R^{N}: \quad \underline{\sigma} \leq\left|x_{n}\right| \leq \bar{\sigma}, \quad n=1, \ldots, N\right\}
$$

be the path space with the canonical process

$$
X_{k}(\omega):=x_{k} \text { for } \omega=\left(x_{1}, \ldots, x_{N}\right) \in \Omega
$$

and the canonical filtration

$$
\mathcal{F}_{n}:=\sigma\left(X_{1}, \ldots, X_{n}\right), n=0, \ldots, N
$$

For every $n=0, \ldots, N$ the cost of buying one share of the stock at time $n$ is $S_{n}(1+\lambda)$, where $\lambda \in[0, \infty)$ and the amount received for selling one share at time $n$ is $S_{n}(1-\mu)$ with $\mu \in[0,1)$. A trading strategy is a pair $(\eta, \theta)$ of predictable processes $\eta_{n}, \theta_{n}$ representing positions in cash and stock respectively, at $n=0, \ldots, N$. The time $n$ liquidation value $\vartheta_{n}$ of a portfolio $(\alpha, \beta)$ of cash and stock is defined as

$$
\vartheta_{n}(\alpha, \beta)=\alpha+\beta^{+}(1-\mu) S_{n}-\beta^{-}(1+\lambda) S_{n}
$$

Definition 1. A pair $(\eta, \theta)$ of predictable processes $\eta_{n}, \theta_{n}$, can be called a self-financing strategy, if

$$
\vartheta_{n}\left(\eta_{n}-\eta_{n+1}, \theta_{n}-\theta_{n+1}\right) \geq 0
$$

for each $n=0, \ldots, N$, with $\theta_{0}=0$.

The class of self-financing strategies starting with initial capital shall be denoted by $\eta_{0}$ by $\Phi\left(\eta_{0}\right)$.

Definition 2. The super-replication price of a European option $F: \mathbb{R}_{+}^{N+1} \rightarrow \mathbb{R}_{+}$ is defined as

$$
\begin{gathered}
\pi_{\underline{\sigma}, \bar{\sigma}}(F)=\inf \left\{\eta_{0} \in \mathbb{R} \mid \exists(\eta, \theta) \in \Phi\left(\eta_{0}\right):\right. \\
\left.\vartheta_{N}\left(\eta_{N}(\omega)-F(S(\omega)), \theta_{N}(\omega)\right) \geq 0 \quad \forall \omega \in \Omega_{\underline{\sigma}, \bar{\sigma}}\right\} .
\end{gathered}
$$

The aim here is to determine the minimal initial capital which allows one, by using self-financing strategy, to end up holding a solvent portfolio $\left(\eta_{N}(\omega)-F(S(\omega)), \theta_{N}(\omega)\right)$, by delivering the payoff $F(S)$ at time $N$. It should be emphasised that super-replication prices are not defined in an almost sure sense, as in the classical approach. 


\section{The Main Result}

We consider the special case of a convex payoff profile and show that the superreplication price coincides with the one computed in the binomial model where the volatility always takes its maximal values. This result allows for the investigation to be continued in the finite path space and, consequently, for an algorithmic approach to the optimal super-replication of European options considered in (Roux, Tokarz \& Zastawniak 2008) to be used.

Theorem 3. Suppose that the payoff function $F: \mathbb{R}_{+}^{N+1} \rightarrow \mathbb{R}_{+}$is convex. The super-replication price of any European option with payoff $F$ is then given by

$$
\pi_{\underline{\sigma}, \bar{\sigma}}(F)=\bar{\pi}(F)
$$

where $\bar{\pi}(F)=\pi_{\bar{\sigma}, \bar{\sigma}}(F)$ denotes the super-replication price of $F(S)$ in the binomial model with volatility $\bar{\sigma}$ and transaction costs $\lambda, \mu$.

A similar result for markets with friction is shown in (Bank, Dolinsky \& Gökay 2016). Note that in (Bank, Dolinsky \& Gökay 2016), the mark-to-market value rather than the liquidation value is considered. Moreover, this approach is based on a different definition of the self-financing strategy.

Proof. Note that $\pi_{\underline{\sigma}, \bar{\sigma}}(F) \geq \bar{\pi}(F)$. It suffices to show that for any $\varepsilon>0$ there exists a self-financial strategy $(\eta, \theta)$ which super-replicates $F(S)$ in every scenario $\omega \in \Omega$ with initial position $(\varepsilon+\bar{\pi}(F), 0)$. Consider the binomial model with volatility $\bar{\sigma}$. Let $\bar{\Omega}=\{-1,1\}^{N}$ be the path space with canonical process $\bar{X}_{n}(\bar{\omega}):=\bar{x}_{n}$ for $\bar{\omega}=\left(\bar{x}_{1}, \ldots, \bar{x}_{N}\right) \in \bar{\Omega}$ and the stock price evolution $\bar{S}_{0}=s_{0}$ and $\bar{S}_{n}=\bar{S}_{n-1} \exp \left(\bar{\sigma} \bar{X}_{n}\right), n=1, \ldots, N$. Clearly, the canonical filtration

$$
\overline{\mathcal{F}}_{n}:=\sigma\left(\bar{X}_{1}, \ldots, \bar{X}_{n}\right), n=0, \ldots, N
$$

coincides with the one generated by $\bar{S}=\left(\bar{S}_{n}\right)_{n=0, \ldots, N}$. By the definition of $\bar{\pi}(F)$ there is $\left(\overline{\mathcal{F}}_{n}\right)_{n=0, \ldots, N}$-predictable process $(\bar{\eta}, \bar{\theta})$ such that with $\bar{\theta}_{0}=0$. We therefore have

$$
\begin{gathered}
\vartheta_{0}\left(\varepsilon+\bar{\pi}(F)-\bar{\eta}_{1}, \bar{\theta}_{0}-\bar{\theta}_{1}\right) \geq 0 \\
\vartheta_{n}\left(\bar{\eta}_{n}-\bar{\eta}_{n+1}, \bar{\theta}_{n}-\bar{\theta}_{n+1}\right) \geq 0, \quad n=1, \ldots, N-1 \\
\vartheta_{N}\left(\bar{\eta}_{N}-F(\bar{S}), \bar{\theta}_{N}\right) \geq 0
\end{gathered}
$$

everywhere on $\bar{\Omega}$. In view of inequalities (2) for any $\omega \in \Omega$ and $n=1, \ldots, N$ there are unique weights $w_{n}^{(+1)}(\omega), w_{n}^{(-1)}(\omega) \geq 0$ with $w_{n}^{(+1)}(\omega)+w_{n}^{(-1)}(\omega)=1$ such that 
Super-replication of European Options...

$$
e^{X_{n}(\omega)}=w_{n}^{(+1)}(\omega) e^{\bar{\sigma}}+w_{n}^{(-1)}(\omega) e^{-\bar{\sigma}} .
$$

Observe that for weights

$$
w_{n}^{\bar{\omega}^{n}}(\omega):=\prod_{m=1}^{n} w_{n}^{\left(\bar{\omega}_{m}^{n}\right)}(\omega), \bar{\omega}^{n}=\left(\bar{\omega}_{1}^{n}, \ldots, \bar{\omega}_{n}^{n}\right) \in\{-1,1\}^{n}
$$

we have

$$
\sum_{\bar{\omega}^{n} \in\{-1,1\}^{n}} w_{n}^{\bar{\omega}^{n}}(\omega)=\prod_{m=1}^{n}\left(w_{m}^{(+1)}(\omega)+w_{m}^{(-1)}(\omega)\right)=1
$$

for $n=1, \ldots, N$ and

$$
w_{n}^{\bar{\omega}^{n}}(\omega)=w_{n}^{\bar{\omega}^{n}}(\omega) \prod_{m=n+1}^{N}\left(w_{m}^{(+1)}(\omega)+w_{m}^{(-1)}(\omega)\right)=\sum_{\bar{\omega}^{N-n} \in\{-1,1\}^{N-n}} w_{N}^{\left(\bar{\omega}^{n}, \bar{\omega}^{N-n}\right)}(\omega) .
$$

By using (3), (14), (17) and the adaptedness of $\bar{S}$ we get the following representation:

$$
\begin{gathered}
S_{n}(\omega)=s_{0} \prod_{m=1}^{n}\left(w_{m}^{(+1)}(\omega) e^{\bar{\sigma}}+w_{m}^{(-1)}(\omega) e^{-\bar{\sigma}}\right) \\
=\sum_{\bar{\omega}^{n} \in\{-1,1\}^{n}} \bar{S}_{n}\left(\bar{\omega}^{n}, 1, \ldots, 1\right) w_{n}^{\bar{\omega}^{n}}(\omega)=\sum_{\bar{\omega} \in \bar{\Omega}} \bar{S}_{n}(\bar{\omega}) w_{N}^{\bar{\omega}}(\omega)
\end{gathered}
$$

for any $n=1, \ldots, N, \omega \in \Omega$. Now consider the pair $(\eta, \theta)$ of predictable processes $\eta_{n}, \theta_{n}$ :

$$
\begin{gathered}
\eta_{n}(\omega):=\left\{\begin{array}{cc}
\varepsilon+\bar{\pi}(F), & n=0 \\
\bar{\eta}_{1}, & n=1 \\
\theta_{n}(\omega):=\left\{\begin{array}{cc}
\bar{\eta}_{n}\left(\bar{\omega}^{n-1}, 1, \ldots, 1\right) w_{n-1}^{\bar{\omega}^{n-1}}(\omega), & n=2, \ldots, N
\end{array}\right. \\
\begin{array}{ccc}
1 & n=0
\end{array} \\
\sum_{\bar{\omega}^{n-1} \in\{-1,1\}^{n-1}} \bar{\theta}_{1} \bar{\theta}_{n} \bar{S}_{n-1}\left(\bar{\omega}^{n-1}, 1, \ldots, 1\right) w_{n-1}^{\bar{\omega}^{n-1}}(\omega), & n=2, \ldots, N .
\end{array}\right.
\end{gathered}
$$

First we prove that the strategy $(\eta, \theta)$ is self-financing. In view of $(11),(7),(16)$, (19) and (20) we have

$$
\begin{gathered}
0 \leq \sum_{\bar{\omega} \in \bar{\Omega}} w_{N}^{\bar{\omega}}(\omega) \vartheta_{0}\left(\varepsilon+\bar{\pi}(F)-\bar{\eta}_{1}(\bar{\omega}), \bar{\theta}_{0}(\bar{\omega})-\bar{\theta}_{1}(\bar{\omega})\right) \\
=\vartheta_{0}\left(\varepsilon+\bar{\pi}(F)-\bar{\eta}_{1}(\bar{\omega}), \bar{\theta}_{0}(\bar{\omega})-\bar{\theta}_{1}(\bar{\omega})\right) \\
=\vartheta_{0}\left(\varepsilon+\bar{\pi}(F)-\eta_{1}(\omega), \theta_{0}(\omega)-\theta_{1}(\omega)\right) .
\end{gathered}
$$


Observe that

$$
\sum_{\bar{\omega} \in \bar{\Omega}} w_{N}^{\bar{\omega}}(\omega) \bar{\eta}_{n}(\bar{\omega})=\sum_{\bar{\omega}^{n-1} \in\{-1,1\}^{n-1}} w_{n-1}^{\bar{\omega}^{n-1}}(\omega) \bar{\eta}_{n}\left(\bar{\omega}^{n-1}, 1, \ldots, 1\right)=\eta_{n}(\omega)
$$

for any $n=1, \ldots, N, \omega \in \Omega$. Since $\bar{\theta}$ is predictable with respect to the filtration $\left(\overline{\mathcal{F}}_{n}\right)_{n=0, \ldots, N}$ and $\bar{S}$ is $\left(\overline{\mathcal{F}}_{n}\right)_{n=0, \ldots, N}$-adapted we have

$$
\begin{aligned}
\sum_{\bar{\omega} \in \bar{\Omega}} w_{N}^{\bar{\omega}}(\omega) \bar{\theta}_{n+1}(\bar{\omega}) \bar{S}_{n}(\bar{\omega}) & =\sum_{\bar{\omega}^{n} \in\{-1,1\}^{n}} w_{n}^{\bar{\omega}^{n}}(\omega)\left(\bar{\theta}_{n+1} \bar{S}_{n}\right)\left(\bar{\omega}^{n}, 1, \ldots, 1\right)= \\
& =\theta_{n+1}(\omega) S_{n}(\omega)
\end{aligned}
$$

for any $n=1, \ldots, N, \omega \in \Omega$ and

$$
\begin{gathered}
\sum_{\bar{\omega} \in \bar{\Omega}} w_{N}^{\bar{\omega}}(\omega) \bar{\theta}_{n}(\bar{\omega}) \bar{S}_{n}(\bar{\omega})=\sum_{\bar{\omega}^{n} \in\{-1,1\}^{n}} w_{n}^{\bar{\omega}^{n}}(\omega)\left(\bar{\theta}_{n} \bar{S}_{n}\right)\left(\bar{\omega}^{n}, 1, \ldots, 1\right)= \\
=\sum_{\bar{\omega}^{n-1} \in\{-1,1\}^{n-1} \bar{x} \in\{-1,1\}} w_{n-1}^{\bar{\omega}_{n-1}}(\omega) w_{n}^{\bar{x}}(\omega)\left(\bar{\theta}_{n} \bar{S}_{n}\right)\left(\bar{\omega}^{n-1}, \bar{x}, \ldots, 1\right)= \\
=\sum_{\bar{\omega}^{n-1} \in\{-1,1\}^{n-1}} w_{n-1}^{\bar{\omega}^{n-1}}(\omega)\left(\bar{\theta}_{n} \bar{S}_{n-1}\right)\left(\bar{\omega}^{n-1}, 1, \ldots, 1\right)\left[w_{n}^{(+1)}(\omega) e^{\bar{\sigma}}+w_{n}^{(-1)}(\omega) e^{-\bar{\sigma}}\right]= \\
=\theta_{n}(\omega) S_{n-1}(\omega) e^{X_{n}(\omega)}=\theta_{n}(\omega) S_{n}(\omega)
\end{gathered}
$$

for any $n=2, \ldots, N-1, \omega \in \Omega$. Now, using (12) and (7) we obtain

$$
\begin{gathered}
0 \leq \sum_{\bar{\omega} \in \bar{\Omega}} w_{N}^{\bar{\omega}}(\omega) \vartheta_{n}\left(\bar{\eta}_{n}(\bar{\omega})-\bar{\eta}_{n+1}(\bar{\omega}), \bar{\theta}_{n}(\bar{\omega})-\bar{\theta}_{n+1}(\bar{\omega})\right)= \\
=\sum_{\bar{\omega} \in \bar{\Omega}} w_{N}^{\bar{\omega}}(\omega)\left(\bar{\eta}_{n}(\bar{\omega})-\bar{\eta}_{n+1}(\bar{\omega})\right)+\sum_{\bar{\omega} \in \bar{\Omega}} w_{N}^{\bar{\omega}}(\omega)\left(\bar{\theta}_{n}(\bar{\omega})-\bar{\theta}_{n+1}(\bar{\omega})\right) \bar{S}_{n}(\bar{\omega})+ \\
-\mu \sum_{\bar{\omega} \in \bar{\Omega}} w_{N}^{\bar{\omega}}(\omega)\left(\bar{\theta}_{n}(\bar{\omega})-\bar{\theta}_{n+1}(\bar{\omega})\right)^{+} \bar{S}_{n}(\bar{\omega})+ \\
-\lambda \sum_{\bar{\omega} \in \bar{\Omega}} w_{N}^{\bar{\omega}}(\omega)\left(\bar{\theta}_{n}(\bar{\omega})-\bar{\theta}_{n+1}(\bar{\omega})\right)^{-} \bar{S}_{n}(\bar{\omega})
\end{gathered}
$$

for any $n=1, \ldots, N-1, \omega \in \Omega$, which in conjunction with (22), (23), (24) and the convexity of the positive and the negative part entails the inequality

$$
0 \leq \vartheta_{n}\left(\eta_{n}(\omega)-\eta_{n+1}(\omega), \theta_{n}(\omega)-\theta_{n+1}(\omega)\right)
$$

for any $n=1, \ldots, N-1, \omega \in \Omega$. The super-replication condition

$$
\vartheta_{N}\left(\eta_{N}(\omega)-F(S), \theta_{N}(\omega)\right) \geq 0
$$

for $\omega \in \Omega$ remains to be proved. By definition of $\vartheta_{n}$ and (13) we have 


$$
\begin{gathered}
0 \leq \sum_{\bar{\omega} \in \bar{\Omega}} w_{N}^{\bar{\omega}}(\omega) \vartheta_{N}\left(\bar{\eta}_{N}(\bar{\omega})-F(\bar{S}(\bar{\omega})), \bar{\theta}_{N}(\bar{\omega})\right)= \\
=\sum_{\bar{\omega} \in \bar{\Omega}} w_{N}^{\bar{\omega}}(\omega)\left(\bar{\eta}_{N}(\bar{\omega})-F(\bar{S}(\bar{\omega}))\right)+\sum_{\bar{\omega} \in \bar{\Omega}} w_{N}^{\bar{\omega}}(\omega) \bar{\theta}_{N}(\bar{\omega}) \bar{S}_{N}(\bar{\omega})+ \\
-\mu \sum_{\bar{\omega} \in \bar{\Omega}} w_{N}^{\bar{\omega}}(\omega)\left(\bar{\theta}_{N}(\bar{\omega})\right)^{+} \bar{S}_{N}(\bar{\omega})-\lambda \sum_{\bar{\omega} \in \bar{\Omega}} w_{N}^{\bar{\omega}}(\omega)\left(\bar{\theta}_{N}(\bar{\omega})\right)^{-} \bar{S}_{N}(\bar{\omega}) .
\end{gathered}
$$

Note that

$$
\begin{gathered}
\sum_{\bar{\omega} \in \bar{\Omega}} w_{N}^{\bar{\omega}}(\omega) F(\bar{S}(\bar{\omega})) \geq F\left(\sum_{\bar{\omega} \in \bar{\Omega}} w_{N}^{\bar{\omega}}(\omega) \bar{S}_{0}(\bar{\omega}), \ldots, \sum_{\bar{\omega} \in \bar{\Omega}} w_{N}^{\bar{\omega}}(\omega) \bar{S}_{N}(\bar{\omega})\right)= \\
=F\left(S_{0}(\omega), \ldots, S_{N}(\omega)\right)=F(S(\omega))
\end{gathered}
$$

due to the convexity of $F: \mathbb{R}_{+}^{N+1} \rightarrow \mathbb{R}_{+}$and (18). Similarly,

$$
\begin{aligned}
& \mu \sum_{\bar{\omega} \in \bar{\Omega}} w_{N}^{\bar{\omega}}(\omega)\left(\bar{\theta}_{N}(\bar{\omega})\right)^{+} \bar{S}_{N}(\bar{\omega}) \geq \mu \theta_{N}^{+}(\omega) S_{N}(\omega) \\
& \lambda \sum_{\bar{\omega} \in \bar{\Omega}} w_{N}^{\bar{\omega}}(\omega)\left(\bar{\theta}_{N}(\bar{\omega})\right)^{-} \bar{S}_{N}(\bar{\omega}) \geq \lambda \theta_{N}^{-}(\omega) S_{N}(\omega) .
\end{aligned}
$$

As a consequence,

$$
\begin{gathered}
0 \leq \sum_{\bar{\omega} \in \bar{\Omega}} w_{N}^{\bar{\omega}}(\omega) \vartheta_{N}\left(\bar{\eta}_{N}(\bar{\omega})-F(\bar{S}(\bar{\omega})), \bar{\theta}_{N}(\bar{\omega})\right) \\
\leq \vartheta_{N}\left(\eta_{N}(\omega)-F(S(\omega)), \theta_{N}(\omega)\right)
\end{gathered}
$$

This shows that the self-financing strategy $(\eta, \theta)$ super-replicates $F(S)$ with $\eta_{0}=\varepsilon+\bar{\pi}(F)$, which completes the proof.

\section{Consequences and Further Generalisations}

In setup used for this paper, all possible stock price evolutions which respect the specified volatility bounds are uncountable, but in view of Theorem 3 , from Theorem 4.2 in (Roux, Tokarz \& Zastawniak 2008), corollary 4 is obtained.

Corollary 4. The super-replication price of a European option with convex payoff $F(S)$ is given by

$$
\pi_{\underline{\sigma}, \bar{\sigma}}(F)=\max _{(\mathbb{P}, \hat{S}) \in \mathcal{P}} \mathbb{E}_{\mathrm{P}}(F(S))=\max _{x \in \mathbb{R}} Z_{0}^{x}-(1+\lambda) S_{0}
$$

where $\mathcal{P}$ denotes the set of pairs $(\mathbb{P}, \hat{S})$ such that $\mathbb{P}$ is probability measure on $\bar{\Omega}$ and $\hat{S}$ is a martingale under $\mathbb{P}$ satisfying 


$$
S_{n}(1-\mu) \leq \widehat{S}_{n} \leq S_{n}(1+\lambda)
$$

for any $n=0, \ldots, N, Z_{0}$ is the polyhedral proper convex function constructed as follows:

- we put

$$
Z_{N}^{x}=\widetilde{Z}_{N}^{x}=\left\{\begin{array}{cc}
F(S)+x & \text { if } x \in\left[S_{N}(1-\mu), S_{N}(1+\lambda)\right] \\
-\infty & \text { if } x \notin\left[S_{N}(1-\mu), S_{N}(1+\lambda)\right]
\end{array}\right.
$$

- for any $n=0, \ldots, N-1$ we take

$$
\widetilde{Z}_{n}\left(\bar{\omega}^{n}\right)=\operatorname{cap}\left\{Z_{n+1}\left(\bar{\omega}^{n+1}\right): \bar{\omega}^{n+1} \in\left\{\left(\bar{\omega}^{n}, 1\right),\left(\bar{\omega}^{n},-1\right)\right\}\right\}
$$

(the concave cap $\operatorname{cap}\left\{f_{1}, \ldots, f_{n}\right\}$ of functions $f_{1}, \ldots, f_{n}: \mathbb{R} \rightarrow \mathbb{R} \cup\{-\infty\}$ is defined as the smallest concave function $h$ such that $h \geq \max \left\{f_{1}, \ldots, f_{n}\right\}$ )

and

$$
Z_{n}^{x}=\left\{\begin{array}{rr}
\widetilde{Z}_{n}^{x} & \text { if } x \in\left[S_{n}(1-\mu), S_{n}(1+\lambda)\right] \\
-\infty & \text { if } x \notin\left[S_{n}(1-\mu), S_{n}(1+\lambda)\right] .
\end{array}\right.
$$

This method makes it possible to price the European option algorithmically, as was studied in (Roux, Tokarz \& Zastawniak 2008).

This paper has examined proportional transaction costs, the results of which can be extended to convex transaction costs. Further extension will consider multi-asset cases and generalize the results in this direction.

\section{Bibliography}

Bank P., Dolinsky Y., Gökay S. (2016), Super-replication with Nonlinear Transaction Costs and Volatility Uncertainty, "The Annals of Applied Probability", vol. 26, no 3, https://doi.org/10.1214/15-aap1130.

Guasoni P., Lépinette E., Rásonyi M. (2012), The Fundamental Theorem of Asset Pricing under Transaction Costs, "Finance and Stochastics", vol. 16, no 4, https://doi. org/10.1007/s00780-012-0185-0.

Guasoni P., Rásonyi M., Schachermayer W. (2008), Consistent Price Systems and Facelifting Pricing under Transaction Costs, "The Annals of Applied Probability", vol. 18, no 2, https://doi.org/10.1214/07-aap461.

Jouini E., Kallal H. (1995), Martingales and Arbitrage in Securities Markets with Transaction Costs, "Journal of Economic Theory", vol. 66, no 1, https://doi.org/ 10.1006/jeth.1995.1037.

Kociński M. (2004), Hedging of the European Option in Discrete Time under Proportional Transaction Costs, "Mathematical Methods of Operations Research", vol. 59, no 2, https://doi.org/10.1007/s001860300323. 
Roux A., Tokarz K., Zastawniak T. (2008), Options under Proportional Transaction Costs: An Algorithmic Approach to Pricing and Hedging, "Acta Applicandae Mathematicae", vol. 103, no 2, https://doi.org/10.1007/s10440-008-9231-5.

Schachermayer W. (2003), Introduction to the Mathematics of Financial Markets (in:) S. Albeverio, W. Schachermayer, M. Talagrand, Lectures on Probability Theory and Statistics, Saint-Flour Summer School 2000, P. Bernard (ed.), Lecture Notes in Mathematics 1816, Springer Verlag, Heidelberg.

Stettner Ł. (1997), Option Pricing in the CRR Model with Proportional Transaction Costs: A Cone Transformation Approach, "Applicationes Mathematicae", vol. 24, no 4, https://doi.org/10.4064/am-24-4-475-514.

\section{Superreplikacja opcji europejskich o wypukłej funkcji wypłaty przy proporcjonalnych kosztach transakcji}

(Streszczenie)

W artykule przedstawiono superreplikację instrumentów pochodnych na rynku finansowym z czasem dyskretnym z proporcjonalnymi kosztami transakcji. O dynamice cen akcji zakładano wyłącznie, że stopy zwrotu są ograniczone. Rozpatrywano klasę europejskich opcji zależnych od trajektorii, o nieujemnych, wypukłych funkcjach wypłaty. Udowodniono, że problem wyceny tego typu opcji można zredukować do wyceny w odpowiednim modelu dwumianowym. Pokazano zatem, że algorytm wyceny, będący w istocie algorytmem programowania dynamicznego na drzewie, może zostać wykorzystany, w przypadku gdy przestrzeń możliwych scenariuszy nie jest skończona.

Słowa kluczowe: superreplikacja, koszty transakcji, niepewność modelu, opcje europejskie. 